\title{
Breast Cancer Locator
}

National Cancer Institute

\section{Source}

National Cancer Institute. Breast Cancer Locator. NCI Thesaurus. Code C142819.

A 3D-printed form that matches a patient's breast shape while in the supine MRI and surgical position. The form includes an outline of the breast cancer on the breast surface, at the point where the cancer is closest to the skin, and includes cylinders for precise placement of marker dye and a marker wire. 